
\title{
$\iiint \begin{gathered}\text { MAQUINARIAS DE GUERRA E MORTES JUVENIS NAS } \\ \text { PERIFERIAS DO CEARÁ }\end{gathered}$
}

\section{Revista de Psicologia}

\author{
PERIFERIAS DO CEARÁ
}

WAR MACHINES AND JUVENILE DEATHS IN THE PERIPHERIES OF CEARÁ

\author{
João Paulo Pereira Barros ${ }^{1}$ \\ Filipe Augusto Barbosa Alencar ${ }^{2}$ \\ Dagualberto Barboza da Silva ${ }^{3}$
}

\section{Resumo}

O objetivo deste artigo é problematizar como maquinarias de guerra em territorialidades periferizadas operam na produção de juventudes matáveis no bojo da intensificação da violência letal no Brasil, tomando a cidade de Fortaleza como exemplo empírico e as noções de necropolítica e políticas de inimizade, de Achille Mbembe, como operadores conceituais. Num primeiro momento, traz reflexões teóricas sobre essa própria tecnologia de gestão e produção da morte. Num segundo momento, analisa-se como "maquinarias de guerra" engendram "zonas de morte", sendo a articulação entre disciplinamento, regulação biopolítica e produção/gestão de um "fazer morrer" característica da ocupação colonial na atualidade. Com isso, apontamos como o recrudescimento da violência letal nas margens urbanas expressa sua condição de colônias contemporâneas, em que processos de racialização maximizam a precarização de corpos juvenis negros, sob o fundamento da perpetuação de relações de inimizade.

Palavras-chave: Violência; Juventude; Necropolítica.

\section{Abstract}

The aims of this article is to discuss the war strategies in peripheral territorialities, operating in the production of new non-intense forms of lethal violence in Brazil, taking the city of Fortaleza as an empirical example and uses Achille Mbembe's notion of necropolitics as the main conceptual operator. At first, brings theoretical reflections from the dialogs that Mbembe weaves with Foucault, Agamben, Arendt and Fanon. Secondly, parses as "war machines" engender "death zones, being the link between discipline, biopolitical production and regulation/management of a "do die" feature of colonial occupation today. With this, we point out how the escalation of deadly violence in the urban margins expressed your condition of contemporary colonies, in which racionalitation processes maximize precariousness of black youth bodies, under the foundation of perpetuation of enmity.

Keywords: Violence; Youth; Necropolitics.

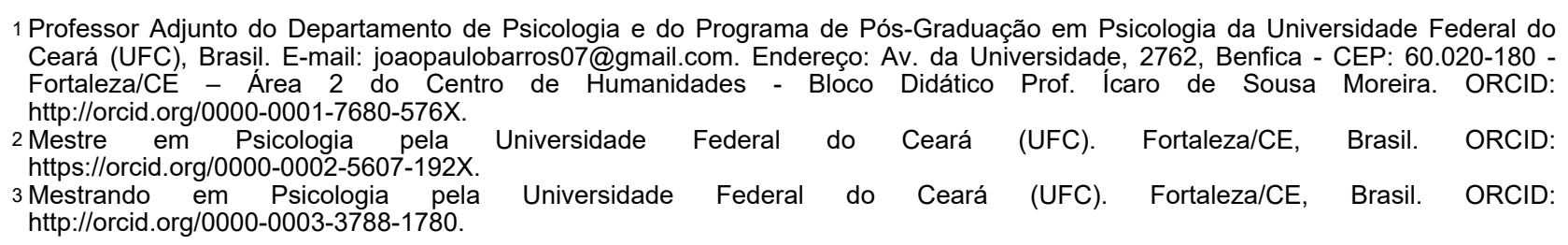




\section{INTRODUÇÃO}

Dados do $12^{\circ}$ Anuário Brasileiro de Segurança Pública retratam a gravidade da problemática das mortes violentas intencionais perpetradas no Brasil. Observa-se, todavia, que este processo tem sido mais intenso na região Nordeste do país (Barros, Paiva, Rodrigues, Leonardo \& Silva, 2018), tendo como destaque dois de seus estados com as maiores taxas de letalidade: Rio Grande do Norte em primeiro, com a taxa de 68,0 por 100 mil habitantes, e Ceará em terceiro, com 59,1.

Em ritmo ainda mais preocupante, os números relativos a homicídios na adolescência também têm se acentuado. De acordo com Melo e Cano (2017), dos 9 estados brasileiros com maior Índice de Homicídios na Adolescência (IHA), 8 são do Nordeste. Nesse quadro, o Ceará aparece como o estado brasileiro com maior IHA. Em relação às capitais brasileiras, Fortaleza desponta como a segunda mais violenta do país (Fórum Brasileiro de Segurança Pública, 2018), além de ser a cidade que apresenta o maior IHA entre as capitais brasileiras (Melo \& Cano, 2017) e ter apresentado um crescimento de 91\% na vitimização de adolescentes (CCPHA - Comitê Cearense pela Prevenção de Homicídios na Adolescência, 2018).

O estado do Ceará registrou também o maior número de crimes violentos letais e intencionais de sua história em 2017, totalizando 5.134 e, portanto, tendo um acréscimo de 48\% nos homicídios em comparação com 2016. Desse total, 981 homicídios foram de adolescentes, ou, em outra leitura, quase 19 adolescentes foram mortos por semana, em grande parte do sexo masculino. Porém, também é necessário apontar o alarmante aumento de 196\% da morte de adolescentes do sexo feminino em 2017 (CCPHA, 2018).

Diante desse panorama de intensificação da violência letal no Brasil, este artigo objetiva problematizar como maquinarias de guerra em territorialidades periferizadas operam na produção de juventudes matáveis, tomando a cidade de Fortaleza como exemplo empírico, pelas justificativas acima expostas, e as noções de necropolítica e política de inimizade, de Achille Mbembe, como operadores conceituais. $O$ artigo é um desdobramento teórico de uma pesquisa-intervenção sobre violência urbana, juventude e modos de subjetivação, que tem como um de seus objetivos específicos analisar psicossocialmente a problemática dos homicídios na capital do Ceará.

Nas próximas seções, a problematização é composta, em seu primeiro momento, por uma discussão teórica sobre relações entre biopoder e necropoder, explorando diálogos de Mbembe com autores como Foucault e Agamben. Em seguida, tomamos a noção de necropolítica como uma tecnologia de poder que implica a produção e gestão de modos de fazer morrer, a partir da produção de corpos matáveis, o que nos ajuda a compreender como certos adolescentes e jovens, a partir de uma sociedade cada vez mais punitivista, de seus processos de racialização que remontam a colonialidade e da operação de maquinarias de guerra acentuadas por políticas de inimizade, encarnam a condição de inimigos a serem aniquilados, destituídos de estatuto político e da própria condição de humanos.

\section{ARTICULAÇÕES ENTRE NECROPOLÍTICA E BIOPOLÍTICA: APRIMORANDO FERRAMENTAS TEÓRICAS}

Ao interrogar os modos como os seres humanos tornam-se "sujeitos", na sua relação com saberes, poderes e consigo, Michel Foucault (1995) propõe uma analítica do "poder" a partir de "como" ele estrategicamente se exerce em 
rede e microfisicamente. Assim, o autor, a partir de um exercício arquegenealógico, salienta que o poder "só existe em ato", sendo seu exercício "um modo de ação de alguns sobre outros" (p. 242).

A "assunção da vida pelo poder" (Foucault, 2005, p. 286) teria sido um dos fenômenos fundamentais do século XIX. O poder em uma sociedade de soberania seria, em suma, "direito de apreensão das coisas, do tempo, dos corpos e, finalmente, da vida; culminava com o privilégio de se apoderar da vida para suprimi-la". (Foucault, 1999, p. 128). Vida e morte deixariam de pertencer ao campo dos acontecimentos naturais, fazendo parte do campo do poder político (Foucault, 2005).

Durante os séculos XVII e XVIII, ter-se-ia observado a emergência do poder disciplinar, com sua tecnologia e mecanismos voltados para a distribuição espacial e a constituição de todo um campo de visibilidade em torno dos corpos individuais, de modo a torná-los dóceis e majorar sua utilidade econômica, "mediante todo um sistema de vigilância, de hierarquias, de inspeções, de escriturações, de relatórios" (Foucault, 2005, p. 288).

Às disciplinas interessariam os corpos vivos, os quais, quanto mais potencializados, mais produtivos seriam. Efeito de mudanças nas formas de castigo e punição, que passam a ter a subjetividade como seu campo de incidência, o poder disciplinar seria um poder de vida, servindo não só à reprodução das relações de produção, como também constituindo o próprio modo de produção e o próprio indivíduo (Foucault, 2014).

A partir da segunda metade do século XIX, o poder de morte passa a funcionar como complemento de um poder que atuaria na direção de promover a vida, multiplicá-la, regulá-la, ordená-la, sob a perspectiva de "fazer viver" e "deixar morrer". Este poder irá se ocupar não do ser humano como corpo-organismo, mas como corpo-espécie, tecnologia que será operada a partir da articulação de uma "anátomo-política do corpo humano" e uma "biopolítica da população" (Foucault, 1999). Como "efeito histórico de uma tecnologia centrada na vida" (Foucault, 1999, p. 135), tem-se uma sociedade normalizadora, tornando o biopoder imprescindível ao desenvolvimento do capitalismo.

Tomando por base as ponderações de Domenico Losurdo acerca de um suposto eurocentrismo da crítica social tecida por Foucault, Hilário (2016), propondo-se a refletir sobre a maneira como os dispositivos de análise foucaultianos podem servir para problematizações do poder desde as periferias do capitalismo, invoca as proposições de Achille Mbembe sobre necropolítica. Questiona o que aconteceria se a forma social moderna não mais necessitasse apenas produzir a vida para sua manutenção. Argumenta que, durante o período de ascensão e consolidação do capitalismo entre os séculos XVI e XX, viveu-se a assimilação de grandes massas humanas nas fábricas para produção de mercadorias. Já a partir das transformações técnicas ocorridas desde a segunda metade do século XX, a ação do sistema capitalista passou a ser a expulsão daquelas massas, relegando-as ao desemprego estrutural, empurrando-as para as periferias das cidades, para as prisões ou aniquilando-as por meio de forças policiais.

Cunhada após os acontecimentos de 11 de setembro de 2001 nos Estados Unidos, a categoria "necropolítica" (Mbembe, 2006) se refere a uma lógica global que teria passado a fundamentar, a partir dali, a política em noções como a guerra, o terror e o inimigo (Mac Gregor, 2013), destacando-se, com isso, uma prática política baseada na dicotomia amigo-inimigo, na contemporaneidade.

A referida categoria permitiria uma crítica do modelo político fundado na exceção ao explicitar que a lógica da política como administração e trabalho de morte tornara-se a regra. Ressaltando, em pleno século XXI, a marcação racial da produção de vidas descartáveis outrora característica da exploração das terras coloniais, Mbembe (2011, 2017) aponta que políticas de morte estariam intimamente articuladas a processos de racialização. Na época atual do 
capitalismo, já não se trataria nem da assimilação nem da expulsão, já que o sistema se desfaria das massas humanas em larga escala. As grandes massas, outrora indispensáveis à produção de mercadorias, tornam-se descartáveis, supérfluas em relação ao modo de reprodução do sistema e da produção de riquezas (Hilário, 2016).

Enquanto o crescimento da produção de riquezas significava resolução da vida social por meio da inclusão cada vez maior de trabalhadores, a partir da crise sistêmica dos anos 70, optara-se pela manutenção da produção de valor em troca da barbarização dos laços sociais. Emerge então uma política de gestão e produção da morte, "cujo objetivo é a aniquilação em larga escala" (Hilário, 2016, p. 203).

"Fazer morrer" e "deixar viver" constituiriam os limites e principais atributos de um poder que exerce "um controle sobre a mortalidade" e definição da vida "como o desdobramento e a manifestação do poder" (Mbembe, 2011, p. 20). 0 autor camaronês propõe a noção de necropolítica para dar conta de uma discussão sobre "as várias maneiras pelas quais [...] as armas de fogo são dispostas com o objetivo de provocar a destruição máxima de pessoas e criar 'mundos de morte"' (Mbembe, 2017, p. 71).

Ao tecer essa concepção, Mbembe, além de sua interlocução com Fanon sobre colonialidade, articula a categoria de biopolítica aos conceitos de estado de exceção e estado de sítio, a partir de Giorgio Agamben e Hannah Arendt, questionando, dentre outros pontos, se aquela noção foucaultiana seria suficiente para explicar a maneira como a política atual faz do assassinato daqueles que são elevados ao patamar de inimigos seu objetivo principal e definitivo nas periferias do capitalismo.

Mbembe (2011) retoma a discussão foucaultiana de que o biopoder funcionaria dividindo as pessoas em diferentes grupos e subgrupos. Com base nessas divisões, segregaria os sujeitos entre aqueles que devem morrer e os que devem viver, na medida em que estabelece rupturas biológicas entre as pessoas, operando o que, para Foucault (2005), seria um "racismo de estado", responsável pela criação de condições de aceitabilidade da morte em uma sociedade cujo primado é o da normalização da vida. Essa seria, assim, uma tecnologia de funcionamento do biopoder. Em sua formulação sobre necropolítica, Mbembe (2001) recorre diretamente a essa discussão feita por Foucault (2005), no curso Em Defesa da Sociedade, segundo a qual o racismo é crucial para o exercício das funções mortíferas e para a distribuição da morte, sendo a própria condição de aceitabilidade da morte em uma sociedade com aspirações normalizadoras.

O biopoder teria inserido o racismo nos mecanismos do Estado como dispositivo através do qual esse poder de fomentar a vida exerceria a função de matar ou de expor à morte seus cidadãos (Foucault, 2005). 0 racismo, então, teria como funções: 1) criar divisões e hierarquizações de caráter biológico no interior da espécie humana; 2) fazer funcionar de maneira nova a velha relação guerreira em que a morte do inimigo seria garantia da minha própria vida. A novidade introduzida pelo racismo seria uma biologização dessa relação, de modo que "a morte do outro não é simplesmente a minha vida, na medida em que seria minha segurança pessoal; a morte do outro, a morte da raça ruim, da raça inferior (ou do degenerado, ou do anormal), é o que vai deixar a vida em geral mais sadia; mais sadia e mais pura" (Foucault, 2005, p. 305), algo que, para Mbembe $(2011,2017)$, constituiria um dos imaginários próprios da era moderna.

Mbembe ressalta que, nas colônias, a biopolítica e a disciplina se articulariam a uma necropolítica, na medida em que a administração das populações se faria com base em uma lógica de guerra "que legitima a expropriação do território e a distribuição e exploração de seus habitantes sob a significação da vida como descartável ou supérflua" (Mac Gregor, 2013, p. 25). 
Tal mecanismo, no funcionamento do biopoder, teria se desenvolvido concomitantemente ao "genocídio colonizador" implementado pelos Estados europeus ocidentais. "Quando for preciso matar pessoas, matar populações, matar civilizações, como se poderá fazê-lo, se se funcionar no modo do biopoder? Através dos temas do evolucionismo, mediante um racismo." (Foucault, 2005, p. 307). Da mesma forma, o racismo também seria 0 mecanismo através do qual se justificaria a guerra, não somente contra determinados "inimigos" como também a exposição dos próprios "cidadãos" à morte a partir da ideia de purificação da raça (Foucault, 2005).

Ultrapassando a ideia de um ódio entre raças ou de manipulações ideológicas de classes ou grupos dominantes em relação a bodes expiatórios, o racismo seria um mecanismo que permitiria o funcionamento do próprio biopoder. Desta forma,

se o genocídio é, de fato, o sonho dos poderes modernos, não é por uma volta, atualmente, ao velho direito de matar; mas é porque o poder se situa e exerce ao nível da vida, da espécie, da raça e dos fenômenos maciços de população (Foucault, 1999, p. 129).

Assim como Foucault (2005), Mbembe (2011) salienta que a "raça" sempre estivera presente na constituição do pensamento moderno e da prática das políticas ocidentais, principalmente em se tratando de desumanizar povos estrangeiros e subjugá-los. Ressaltando que, para Foucault, o direito soberano de matar e os mecanismos do biopoder seriam os elementos constitutivos do poder no Estado moderno, aponta, no entanto, a escravidão como uma das primeiras manifestações de uma experimentação biopolítica, defendendo sua consideração como indispensável em qualquer relato histórico acerca da emergência do terror moderno.

Na plantation colonial, a dissolução da humanidade do escravo chegaria a tal ponto que se faria possível afirmar que sua vida fosse propriedade de um senhor, tal como uma coisa possuída por alguém. Sua condição seria 0 resultado da perda de um lugar, da perda dos direitos sobre o corpo e da perda do status político. "Esta tripla perda equivale a uma dominação absoluta, a uma alienação desde o nascimento e a uma morte social (que é uma expulsão fora da humanidade)" (Mbembe, 2011, p. 32).

Sob a perspectiva teórica mbembeana, nas colônias teriam se dado as primeiras articulações entre massacre e burocracia, típicas da racionalidade ocidental. Nesses espaços também se fez aparecer esse tipo de terror particular forjado na concatenação do biopoder, do estado de exceção e do estado de sítio, tendo a raça como determinante. Enquanto Foucault exemplifica essa questão através do nazismo, Mbembe atenta para o fato de que as colônias, dentro do imaginário e da prática política europeia, seriam lugares por excelência em que a soberania seria um poder exercido à margem da lei e onde a paz se faria por meio de uma guerra infindável. Tal concepção corresponderia ao entendimento da soberania como "o poder de decidir o estado de exceção" (Mbembe, 2011, p. 37). 0 autor prossegue alertando que a eficácia da colônia como formação do terror moderno deve ser avaliada levando-se em conta a emergência de uma ordem jurídica europeia, que, dentre outros, buscará estabelecer um ordenamento da guerra, em cuja racionalidade o Estado "civilizado" ocupará posição central, cabendo a esse a tarefa de "civilizar" as maneiras de matar e de atribuir objetivos racionais a tal ato.

Vale retomar aqui a polêmica levantada por Hilário (2016) a respeito das discussões de Foucault serem ou não necessárias numa crítica social a partir das periferias do capitalismo, dadas as ponderações feitas por Losurdo sobre um certo eurocentrismo na analítica foucaultiana. Pensamos ser o caso de nos atentarmos para a importância de reinvenções das ferramentas foucaultianas como um modo de vitalizar uma crítica social desde as periferias do capitalismo, sendo a noção de necropolítica um ótimo exemplo disso. $O$ que pode ser notado na proposta da noção de 
necropolítica, que surge da necessidade de pautar a criação de "mundos de morte", está longe de ser um rechaço a Foucault, mas uma reinvenção de uma de suas ferramentas teóricas, a noção de biopoder, a fim de dar conta de um problema, de um campo de práticas e de um contexto distinto dos que receberam atenção do autor francês.

Assim, a categoria necropolítica refere-se a três questões principais: 1) aos contextos nos quais o estado de exceção tomara traços de normalidade; 2) a uma generalizada instrumentalização da existência humana, acompanhada de uma destruição de corpos e populações consideradas descartáveis ou supérfluas; 3) ao apelo contínuo à emergência e a uma noção fantasmática do inimigo. "O termo [...] se refere fundamentalmente a esse tipo de política na qual a política se entende como o trabalho da morte na produção de um mundo em que se acaba com 0 limite da morte" (Mbembe, 2012, pp. 135-136).

A necropolítica permitiria, assim, analisar criticamente a fundamentação da política contemporânea a partir dos modos como se articulam violência e direito, por um lado, e exceção e soberania por outro. 0 diferencial da proposição de Mbembe seria a maneira como ele constrói sua argumentação por meio de uma genealogia crítica de práticas discursivas e não discursivas contemporâneas que justificam a produção de mundos de morte na exceção e atitude da guerra, na figura do inimigo e no terror (Mac Gregor, 2013). Além disso, o autor situa a necropolítica em um contexto que ele chama de "sociedade da inimizade", que se apresenta cada vez mais militarizada, a fim de eliminar esse inimigo, alimentando o medo e a insegurança. Essa sociedade se caracterizaria por uma saída da democracia, compreensão utilizada por Mbembe para fazer uma crítica à democracia liberal, que a despeito de suas retóricas pacifistas, manteve-se de mãos dadas com o imperialismo e o colonialismo.

No próximo tópico, procederemos à explanação acerca das expressões de uma necropolítica operada em territórios das margens urbanas brasileiras, articulando maquinarias de guerra à problemática dos homicídios, notadamente em áreas periféricas da cidade de Fortaleza.

\section{MAQUINARIAS DE GUERRA NAS DINÂMICAS DA VIOLÊNCIA URBANA EM FORTALEZA}

Tendo como mote as inquietações de Achille Mbembe $(2011,2012,2017)$, segundo o qual vivemos em meio a políticas de inimizade, adaptando seu raciocínio para a tentativa de compreensão da problemática dos homicídios de adolescentes e jovens no Brasil, notadamente na cidade de Fortaleza, podemos indagar: quem são os sujeitos das mortes de jovens nas periferias fortalezenses? Como se dá a participação do Estado nessas mortes (em que medida ele "faz" e/ou "deixa" morrer)? Como se manifestam as relações de inimizade entre os elementos desses embates? Para tentar responder a esses questionamentos, destacamos as expressões das maquinarias de guerra que atuam nas dinâmicas da violência urbana na capital cearense, buscando entender como cada uma dessas expressões sustentam e fomentam o atual cenário de recrudescimento dos homicídios de adolescentes e jovens na cidade.

Ao pôr em análise o cenário da violência urbana em Fortaleza, poderíamos afirmar a presença de uma lógica que coloca a morte de certos adolescentes e jovens em relação direta com uma pretensa segurança da figura do "cidadão" em nossa sociedade. Esta relação seria, portanto, além de racial, militar, guerreira e política. A argumentação de que o racismo funcionaria no intuito da eliminação de perigos internos e externos em relação à população parece fazer sentido ao problematizarmos os homicídios de jovens em Fortaleza. Retomando as declarações de autoridades do campo de segurança pública acerca das chacinas que têm sido cada vez mais 
frequentes no estado do Ceará e em sua capital, já abordadas por Paiva (2015) e Barros, Acioly e Ribeiro (2016), nota-se que certos grupos populacionais são destituídos da condição de cidadãos e, assim, aparentemente indignos de direitos humanos.

Foucault (2005) ilustra, quando menciona o nazismo como exemplo do biopoder que leva o funcionamento do racismo ao extremo, como o poder soberano de matar pode ser estendido ao corpo social, permitindo o exercício direto ou indireto do direito de morte por parcelas consideráveis de sujeitos. Simultaneamente, complementando a função de destruição das raças inimigas, o projeto nazista punha em prática a exposição de sua própria população ao risco de morte. "O risco de morrer, a exposição à destruição total, é um dos princípios inseridos entre os deveres fundamentais da obediência nazista, e entre os objetivos essenciais da política". (Foucault, 2005, p. 310).

A ilustração do pensador francês, bem como a questão da violência letal no Brasil, nos instigam a pensar, em primeiro lugar, de que maneira o poder de morte tem se estendido pelo corpo social em nossa sociedade. Por um lado, políticas de segurança que apostam cada vez mais na militarização indicam algo nesse sentido, em que ações empreendidas por agentes do Estado, mesmo à margem da lei, são por vezes toleradas e até mesmo demandadas por parcelas consideráveis da população.

Por outro lado, o crescimento e intensificação da atuação das "faç̧ões" (organizações criminosas que operam no comércio de drogas ilícitas) e de seus conflitos em diversos bairros das periferias de Fortaleza e em cidades do interior, instituindo regras de comportamento e códigos de conduta por meio dos quais realizam julgamentos e assassinatos como forma de punição, além dos inúmeros ataques fatais a membros de organizações rivais ou demais habitantes de territórios em disputa pelas mesmas, seriam também traços importantes do exercício do poder sobre a vida a e morte ao mesmo tempo. Ambos nos dão pistas de um estado de exceção permanente, como salienta Mbembe (2016) em diálogo com Agamben (2004), como base para a operação de maquinarias necropolíticas em territórios periféricos da capital cearense. Nesses territórios que se tornam emblemas desse estado de exceção permanente, como apontam diversos trabalhos que se debruçam sobre o contexto local para lançar reflexões acerca da problemática da violência no Brasil (Cavalcante, 2011; Paiva, 2017; Barros et al., 2018), guerra e paz não se separam, aspecto típico do funcionamento do poder nas colônias, tal qual destaca Mbembe (2017).

As dinâmicas territoriais têm sofrido profundas alterações em contextos marcados pela necropolítica. Em territorialidades marginalizadas de Fortaleza, as disputas entre "facções" impõem restrições à circulação das pessoas sob pena de serem assassinadas ao cruzarem determinadas fronteiras ou estarem "no local errado e na hora errada" (Barros et al., 2018, p. 121). Paiva (2017) aponta para transformações nas dinâmicas da violência urbana no Ceará ocorridas nos últimos anos, ressaltando que as disputas entre grupos criminosos acontecem há muito tempo, porém, com a ressalva de que há peculiaridades nessas disputas atualmente, já que a rivalidade entre os grupos, ou "facções", como passaram a ser chamados localmente, ganham outras proporções com a atuação de grupos vindos de outros estados da federação.

A ascensão das organizações ligadas ao comércio de armas e drogas ilícitas, bem como o aumento de investimentos em estratégias militarizadas de segurança pública e o encarceramento em massa a elas atrelado têm atuado na intensificação de tais transformações (Barros et al., 2018). Barros (2018) salienta ainda que esses fatores, operados com base no paradigma da "guerra às drogas", "que se centra na figura do 'inimigo interno', cada vez mais associada a jovens negros, pobres e do sexo masculino nomeados como 'envolvidos'" (Barros, 2018, pp. 6-7), como dois aspectos chaves para o entendimento do recrudescimento da criminalidade violenta no estado do Ceará. Além 
dos homicídios propriamente ditos, afirma também ser a guerra às drogas, a violência institucional e o encarceramento em massa exemplos de dispositivos através dos quais a necropolítica tem funcionado no Brasil, observando que a intensificação seletiva de homicídios, que é fomentada por essas expressões transparece o real objetivo da referida guerra.

Juliana Borges (2018), ao frisar como a guerra às drogas entra em cena para a ação genocida do Estado contra a população negra, oferece-nos pistas de como a Lei de Drogas, Lei 11.343 de 2006, legitima 0 superencarceramento, cujos efeitos têm sido o de aumentar consideravelmente tanto a população carcerária masculina quanto a feminina, além de nos ajudar a compreender como a articulação do encarceramento em massa com o racismo engendra a necropolítica, já que, segundo a autora, o funcionamento das engrenagens das desigualdades é baseado na hierarquização racial.

O fenômeno da "pacificação" (Paiva, 2017; Barros et al., 2018), ocorrido em 2016, permite notar a dimensão da força e alcance exercido, no estado do Ceará, pelas organizações de comércio de drogas tornadas ilícitas. Paradoxalmente, não deixa de demonstrar a magnitude da capacidade do exercício do poder de morte desses grupos. A "pacificação" tratou-se de uma repactuação entre "facções" possibilitada por alianças, acordos e tréguas. Naquele ano, observou-se redução significativa das taxas de homicídios no estado, além de efeitos positivos entre habitantes das periferias, que vivenciaram redução de crimes como assaltos e puderam voltar a circular livremente pelos territórios (Paiva, 2017). Com a quebra do acordo, no final do mesmo ano, no entanto, os índices de assassinatos voltaram a crescer, chegando ao recorde registrado em 2017 (CCPHA, 2018).

Mbembe (2017) pode nos ajudar a compreender esse quadro ao lançar algumas reflexões sobre as maquinarias de guerra contemporâneas, que têm operado através de "grupos armados, que actuam em prol do Estado, e grupos armados que, não possuindo qualquer Estado, ainda assim controlam vários territórios, acabando 0 alvo de ambos por ser a população civil" (p. 144). A leitura que podemos fazer do contexto brasileiro, e mais especificamente dos contextos cearense e fortalezense, é a de que a maquinaria letal das facções e sua capacidade de instrumentalizar as dinâmicas de territorialidades periferizadas a favor da lucratividade dos mercados ilegais de drogas, gerando mortes e outros efeitos psicossociais, é possibilitada pela ausência do estado social e pela forte presença de um estado penal-policial sob a lógica da repressão e do enfrentamento bélico nas periferias brasileiras, isto é, uma ausência e presença perversas do Estado. Sobre os efeitos da ocupação colonial na atualidade, Mbembe (2017) pontua que

as populações são então desagregadas em rebeldes, crianças-soldados, vítimas ou refugiados, ou em civis mutilados ou apenas torturados [...], enquanto os sobreviventes, depois de um êxodo penoso, ficam confinados a campos e zonas de exceção (p. 143).

No âmbito dos dispositivos de segurança pautadas no paradigma de "guerra às drogas", o extermínio de adolescentes e jovens negros e negras, habitantes de periferias urbanas brasileiras, aparenta, por vezes, ser mero efeito colateral da promessa de "paz", o que é uma pista ao mesmo tempo da continuidade do genocídio negro e das transformações das margens urbanas em zonas de morte através de processos e práticas de militarização. Porém, essa "paz", que nunca se alcança, segue como pano de fundo de uma "guerra sem fim" (Mbembe, 2017). A exemplo do engendramento dessas zonas de morte nas periferias da cidade de Fortaleza, têm-se a criação das chamadas Células de Proteção Comunitária, torres de video-monitoramento instaladas em regiões periféricas, atrelada ao armamento da guarda municipal e expansão do policiamento ostensivo, como emblema da ocupação colonial tardia, já 
que mescla disciplina, biopolítica e necropolítica.

Nessa discussão sobre guerra, que envolve desde a política de segurança calcada na guerra às drogas até os conflitos entre facções, cabe trazer as contribuições de Sayak Triana (2012) sobre necropolítica, entendendo que suas reflexões sobre o México dialogam com o contexto brasileiro. Triana (2012) argumenta que a maquinaria necropolítica possui dimensões econômicas e simbólicas que engendram códigos e interações alicerçados na gestão/produção da morte. Ao analisar a expansão do tráfico no contexto neoliberal, a teórica feminista articula a discussão mbembeana de necropolítica ao que denomina de "capitalismo gore", variante do capitalismo que se refere ao derramamento de sangue banalizado, explícito e espetacularizado, com requintes de crueldade, articulado à precarização econômica e ao que ela chama de necroempoderamento.

A partir do tema da guerra, é possível estabelecer diálogos entre o debate mbembeano sobre necropolítica e as reflexões de Judith Butler (2015) sobre precariedade, vulnerabilidade e vidas (não) passíveis de luto. Assim, temos que um dos efeitos da guerra seria o de maximizar a precariedade de alguns corpos e diminuir a interdependência e responsabilidade entre nós, de forma que algumas vidas, através de enquadramentos perversos, deixam de ser reconhecidas como tal (Butler, 2015). Isso nos leva à necessidade de problematizar o estatuto político de determinados sujeitos, pois, para falar da atuação da necropolítica, é preciso compreender que nem todos são considerados sob o signo da vida e que o aumento ininterrupto de homicídios de certos segmentos populacionais não é um efeito colateral de certas políticas, mas parte de uma lógica que sustenta o regime político atual. Para corroborar essa ideia de que se trata de um projeto e não de uma falha, basta observar que a maior parte desses homicídios, na cidade de Fortaleza, têm ocorrido em bairros que passam por processos históricos de vulnerabilização.

De acordo com levantamento da Secretaria Municipal de Saúde realizado em 2016, 41\% dos adolescentes mortos moravam em 96 territórios com péssimas condições de moradia (CCPHA, 2017), ou seja, além das mortes não se distribuírem de forma homogênea geograficamente, isso evidencia que os assentamentos precários são um elemento importante para entendermos como a necropolítica têm operado nas margens urbanas do Brasil e mais especificamente do Ceará e de sua capital, através da vulnerabilização à morte.

Ainda sobre a possibilidade ou não do reconhecimento como vida, Barros (2018) aponta que os regimes necropolíticos atuam a partir de uma coisificação de sujeitos tidos como "descartáveis", sendo, portanto, indignos de comoção quando de sua morte. Isto é, a comoção seletiva diante de assassinatos seria reflexo justamente da seletividade da própria violência letal, deixando entrever em que medida a necropolítica potencializa e ao mesmo tempo se sustenta na produção de vidas não passíveis de luto (Butler, 2015). Diante de chacinas, a postura comum de autoridades públicas do estado tem sido propriamente atribuir essas mortes a disputas de facções (Paiva, 2017), tornando quase dispensáveis maiores investigações, como mostra a pouquíssima resolução de casos de homicídio que temos em nosso estado.

Ao dialogar com Valois (2017) sobre a "guerra às drogas", compreende-se que as "facções", funcionando segundo os mesmos princípios de mercado que regem empresas de comércio "legal", no limite, exacerbam a lógica mercadológica da competição (guerra). Mas, por óbvio, não a inventaram, ainda que atuem na sua produção e reprodução, inclusive no campo psicossocial. A respeito da lógica de mercado que perpassa o comércio de drogas ilícitas, "a proibição torna o produto mais caro, porque o mercado clandestino tem seus riscos a suportar, mas, ao mesmo tempo, a mercadoria fica mais lucrativa, aliviando os possíveis danos do envolvimento com o tráfico ilícito" (Valois, 2017, p. 97). 
Ressalte-se o papel de estratégias de saber-poder na reprodução do paradigma proibicionista que nascia nos EUA, intimamente ligadas a interesses econômicos de terceiros. Corporações farmacêuticas barganhavam autorizações para o comércio de certas drogas em troca de apoio financeiro e "científico" à política proibicionista (Valois, 2017).

Ao problematizar a produção psicossocial da figura do adolescente/jovem "envolvido" na cidade de Fortaleza, Barros (2018) propõe que essa não se trata da simples imagem do "bandido" ou do jovem "autor de ato infracional". "O 'envolvido' aqui considerado é a principal expressão local dos sujeitos (potencialmente) perigosos, a quem são atribuídas características inerentes de monstruosidade" (Barros, 2018). Salientando o entrelaçamento entre aquela produção, tecnologias políticas de gestão da morte de determinados sujeitos e variações do capitalismo que fomentam tais políticas, o autor afirma ser a produção desses adolescentes/jovens, simultaneamente "morríveis" e "matáveis", um emblema da necropolítica operada no Brasil. Podemos dizer, portanto, que a necropolítica opera potencializando a produção de sujeitos matáveis, aqueles que encarnam o homo sacer de Agamben e cujas vidas não são passíveis de luto, de acordo com a perspectiva butleriana. Isso pode ser corroborado ao nos atentarmos para a pouca comoção social diante do fato de que o maior percentual de homicídios é de negros, o que exemplifica fortemente a articulação entre essa política de morte e política de raça que cria escravos contemporâneos, sujeitos sem lar, corpo e estatuto político (Mbembe, 2017). Não dá para pensar nos homicídios de adolescentes e jovens como emblema da necropolítica sem notar que isso é uma continuidade do racismo, do projeto colonial, do genocídio do negro, como diz Abdias do Nascimento (1978).

Mbembe (2017), ao falar sobre "comunidade de semelhantes" e uma "categoria de não-semelhantes", partindo da caracterização do que ele chama de "democracia de escravos", remete-nos às atuais racionalidades que promovem cisões entre sujeitos, em nossa sociedade, com base em marcadores sociais como cor da pele, gênero, status socioeconômico, local de moradia, dentre outros. Atravessada pelos efeitos de subjetivação de nosso longo período escravista, aquela bifurcação se atualiza na operação diferenciada do dispositivo jurídico na sociedade brasileira. Ainda que toda a população esteja submetida, em tese, à mesma ordem jurídica formal, a mesma lei poderá ser interpretada e aplicada diferencialmente a depender do "grau de cidadania" dos sujeitos. A questão do comércio ilegal de drogas nos dá pistas disso.

Segundo Valois (2017), o sistema judiciário atuaria, semelhantemente à época da ditadura, "como uma justificativa geral do sistema, julgando, condenando ou absolvendo, mas minimizando o estado total de combate e de guerra que se trava nas ruas" (Valois, 2017, p. 346). Tal assertiva nos dá pistas de como o regime necropolítico se espraia por todo o corpo social, valendo-se da ordem jurídica, porém, não se confundindo com ela e operando para além das instituições estatais na produção das mortes de sujeitos indesejáveis.

Hilário (2016) atenta para a dimensão da necropolítica que diz respeito à "destruição material dos corpos e populações humanos julgados como descartáveis e supérfluos" (Mbembe, 2012, p. 135), sendo este sujeito supérfluo aquele que, por ter sua força de trabalho tornada não mais indispensável ao modo de produção e reprodução do capital, passa a ser portador de uma vida matável. Segue colocando que, se a força de trabalho e potencial de consumo de certos sujeitos passam a não mais ser possíveis de lucratividade, tendo em vista sua condição de sobrantes, sua própria morte passa a se constituir como mercadoria geradora de lucro ao capital, como parte de uma economia da violência, já que a socialização no sistema capitalista aconteceria por meio de trocas de mercadorias. 
No caso brasileiro, notadamente no de Fortaleza, em se tratando de adolescentes e jovens trabalhadores(as) do comércio varejista de drogas tornadas ilícitas, nos parece questionável, entretanto, dizer que aqueles se encontram fora do circuito de compra e venda de mercadorias (incluindo-se sua força de trabalho) próprio do capitalismo. Podemos afirmar que são trabalhadores de uma empresa que movimenta quantias volumosas de dinheiro, ainda que a tais funcionários caiba uma parcela ínfima desses dividendos. No entanto, aparentemente, mais do que lucrariam com um trabalho legal (ainda que informal) como os de muitas pessoas moradoras de periferias urbanas. Parece-nos que eles são incluídos na lógica do sistema, mas de maneira perversa, na medida em que são criminalizados e descartabilizados.

A ideologia da segurança nacional, importada dos Estados Unidos para o Brasil no período da Guerra Fria e intensificada durante a ditadura civil-militar, mostra-se refeita no tempo atual transferindo o conceito de inimigo interno do tratamento de crimes "políticos" para a criminalidade "comum" e o trato da violência urbana (Serra \& Zaccone, 2012). Assim, a criação do mito das classes perigosas (Coimbra, 2001), por meio do mito de estamos em guerra, têm justificado lógicas de exceção e supressão de direitos e a banalização da tortura e a ideia de que forças militares é que resolveriam nossa situação. Atualiza, ainda, o ethos das guerras coloniais descrito por Mbembe (2017), nas quais o necropoder se exime de quaisquer obrigações com regulamentações legais em seu empreendimento de extermínio de populações subjugadas e transformadas em "inimigos", materializado na retórica de guerra às drogas, intimamente relacionada à gestão da pobreza e perpetuação do racismo. Gerir a pobreza, necro-biopoliticamente, portanto, é seu objetivo oculto e funciona muito bem, a despeito de seu objetivo manifesto não funcionar, que seria acabar com as drogas (Barros, 2018).

A necropolítica atenderia, assim, aos objetivos do capitalismo em crise estrutural enquanto forma política, na medida em que as questões sociais se tornam insolúveis no interior das instituições sociais do atual sistema. Aqui lançamos mão de alguns questionamentos: o que seria essa tal "crise" do capitalismo? Quem sofreria os efeitos dessas crises? Seus efeitos atingiriam a todos? Será mesmo correto falar em "crise" do capitalismo? Ou será que essas crises não são inerentes a esse sistema que sempre tem se reinventado em suas estratégias de subjetivação e maximização de lucros?

\section{CONSIDERAÇÕES FINAIS}

Utilizando situações vividas no contexto cearense, problematizamos ao longo do texto maquinarias de guerra que operam na produção/gestão de modos de fazer morrer, constituindo, para tanto, certos corpos como matáveis, notadamente adolescentes e jovens de territorialidades periferizadas (des)subjetivados como inimigos a serem aniquilados. Para isso, trabalhamos teoricamente a noção mbembeana de necropolítica para, a partir então, utilizá-la como ferramenta para a análise da intensificação da atuação de organizações de comércio de drogas ilícitas, das políticas de segurança que apostam na militarização e da própria "guerra às drogas" como dispositivo necropolítico.

Por fim, no tocante à articulação dessas expressões, atuação dos grandes dispositivos midiáticos empresariais têm fomentado processos de racialização que maximizam a precarização de corpos juvenis negros, sob o fundamento da perpetuação de relações de inimizade, lançando mão da espetacularização e do medo na criminalização de juventudes pobres e negras (Coimbra, 2001). 
No que se refere à exposição dos sujeitos à morte, cabe mencionar as formas como o medo tem sido estimulado por tais dispositivos midiáticos em grande parte da população, servindo como operador psicossocial da maquinaria necropolítica discutida nas seções anteriores. 0 medo crônico de parcelas da sociedade, precipuamente aqueles considerados "cidadãos de bem" ou simplesmente "cidadãos", fornece condições para a aceitabilidade do extermínio dos segmentos considerados "inimigos" da sociedade, remontando, em grande medida, a um "medo colonial", nas exposições de Mbembe (2017). Em Fortaleza, seu principal alvo seriam os adolescentes e jovens que encarnam a figura fantasmagórica (Mbembe, 2011; 2017) do "envolvido" (Barros, 2018).

Torres (2017), ao questionar sobre como se articulam as produções discursivas sobre a violência envolvendo jovens nas margens urbanas, oferece-nos pistas de como os dispositivos midiáticos, ao fomentarem o medo e a cultura da violência, concorrem para modos de subjetivação e, mais especificamente, para a criminalização de moradores jovens e negros de territorialidades periferizadas.

Ao citar Nilo Batista, Valois (2017) assinala que o medo seria capaz de ganhar status de mercadoria e seria estratégico politicamente, sendo a principal arma da política de drogas como fora da ditadura. "É o medo que sobra como política quando morre o Estado social para dar lugar ao Estado mínimo, mas, sob o regime militar, tornou-se um espectro mais grave, vez que a sociedade inteira estava literalmente sob armas" (Valois, 2017, p. 349). Percebe-se 0 medo, além de operado politicamente, atuando psicossocialmente na produção de políticas de subjetivação imanentes ao autoritarismo (Barros et al, 2017).

O signo da guerra, como emblema das políticas de inimizade contemporâneas, nos acompanha cotidianamente quando a violência urbana é posta em discussão. Diz-se que estaríamos vivendo uma "guerra entre facções"; a política de segurança se posiciona contra o tráfico como se estivesse em uma guerra e a mídia também se vale disso reiterando e/ou produzindo uma lógica bélica. Todavia, quais são os reais efeitos de pensarmos nosso contexto sob 0 signo da guerra? Afinal, não tem feito parte dessa lógica justamente a produção de um efeito de banalização de um massacre contra grupos específicos que figurado entre as principais vítimas de homicídios, à luz de diferentes levantamentos ao longo dos anos?

\section{Referências}

Agamben, G. (2004). Estado de exceção. São Paulo, SP: Boitempo.

Barros, J. P. P. \& Benicio, L. F. S. (2017) "Eles nascem para morrer?" uma análise psicossocial da problemática dos homicídios de jovens na cidade de fortaleza. Revista de Psicologia, 8(2), 34-43. Recuperado de http://www.periodicos.ufc.br/psicologiaufc/article/view/19313

Barros, J. P. P., Acioly, L. F., \& Ribeiro, J. A. D. (2016). Re-tratos da juventude na cidade de Fortaleza: direitos humanos e intervenções micropolíticas. Revista de psicologia, 7(1), 84-93.

Barros, J. P. P., Paiva, L. F. S., Rodrigues, J. S., Silva, D. B. \& Leonardo, C. S. (2018). "Pacificação" nas periferias: discursos sobre as violências e o cotidiano de juventudes em Fortaleza. Revista de Psicologia, $\quad$ 9(1), 117-128. Recuperado de http://www.periodicos.ufc.br/psicologiaufc/article/view/30781 
Batista, V. M. (2012). Adesão subjetiva à barbárie. In: Loic Wacquant e a questão penal no capitalismo neoliberal. Rio de Janeiro: Revan.

Borges, J. (2018) O que é encarceramento em massa? Belo Horizonte, MG: Letramento.

Butler, J. (2016) Quadros de guerra:Quando a vida é passível de luto? (2 ed.). Rio de Janeiro, RJ: Civilização Brasileira.

Cavalcante, R. M. B. (2011). Vidas breves: investigação acerca do assassinato de jovens em Fortaleza. Dissertação de mestrado. Universidade Estadual do Ceará, Programa de Pós-graduação em Políticas Públicas e Sociedade, Fortaleza, CE.

Coimbra, C. (2001). Operação Rio: o mito das classes perigosas. Rio de Janeiro, RJ: Intertexto.

Coimbra, C.; Scheinvar, E. (2012). Subjetividades punitivo-penais. In: V. M. Batista (Org.), Loic Wacquant e a questão penal no capitalismo neoliberal (pp. 59-68). Rio de Janeiro, RJ: Revan.

Comitê Cearense pela Prevenção de Homicídios na Adolescência. (2017). Cada vida importa: relatório do primeiro semestre de 2017 do Comitê Cearense pela Prevenção de Homicídios na Adolescência. Assembléia Legislativa. Fortaleza, CE: Autor. Recuperado de https://www.al.ce.gov.br/phocadownload/relatorio_primeiro_semestre.pdf

Foucault, M. (1995). O sujeito e o poder. Em: Rabinow, P.; Dreyfus, H. Michel Foucault, uma trajetória filosófica: Para além do estruturalismo e da hermenêutica. Rio de Janeiro, RJ: Forense Universitária. 231-249.

Foucault, M. (1999). História da sexualidade I: A vontade de saber (13ª ed.). Rio de Janeiro, RJ: Graal.

Foucault, M. (2005). Em defesa da sociedade. São Paulo, SP: Martins Fontes.

Foucault, M. (2014) Vigiar e punir.Nascimento da prisão. 42. ed. Petrópolis, RJ: Vozes.

Hilário, L. C. (2016). Da necropolítica à biopolítica: variações foucaultiana na periferia do capitalismo. Sapere aude. v. 7, p. 194-210. Recuperado de http://periodicos.pucminas.br/index.php/SapereAude/article/view/P.2177-6342.2016v7n13p194/9735

Mac Gregor, H. C. (2013) Necropolítica: La política como trabajo de muerte. Revista Ábaco, 4(78) 23-30.

Mbembe, A. (2012) Necropolítica: Una revisión crítica. Em: Mac Gregor, H. C. (Org.). Estética y violencia :Necropolítica, militarización y vidas lloradas. México: Muac, 130-139. 
Mbembe, A. (2017). Políticas da inimizade. Lisboa: Antigona.

Mbembe, A. Necropolítica seguido de Sobre el gobierno privado indirecto. [S. I.]: Melusina, 2011.

Melo, D. L. B. \& Cano, I. (2017) . Índice de homicídios na adolescência: IHA 2014. Rio de Janeiro: Observatório de Favelas.

Nascimento, A. (2017) O genocídio do negro brasileiro: Processo de um racismo mascarado. 2. ed. São Paulo, SP: Perspectiva.

Paiva, L. F. S. (2018). Dinâmicas das violências em tempos de facções criminosas no Ceará. (Cada vida importa: relatório do segundo semestre de 2017 do Comitê Cearense pela Prevenção de Homicídios na Adolescência).

Fortaleza, CE: Comitê Cearense pela Prevenção de Homicídios na Adolescência, (2017.2) 23-26. Recuperado de http://cadavidaimporta.com.br/wp-content/uploads/2018/05/Relato\%CC\%81rio-2017.2-CORRIGIDO.pdf

Paiva, L. F. S.(2015). Mortes na periferia: Considerações sobre a chacina de 12 de novembro em Fortaleza. O Público e O Privado, Fortaleza, CE, n. 26, 269-281.

Serra, C. H. A.; Zaccone, O. (2012). Guerra é paz: os paradoxos da política de segurança de confronto humanitário.

Em: Ramos, B. V. et al. Paz armada - Criminologia de cordel. Rio de Janeiro, RJ: Revan.

Torres, F. T. P. (2017). "O sentimento é um só": criminalização da juventude e produção do medo na cobertura televisiva da "Chacina da Messejana". Monografia (Especialização) - Curso de Psicologia, Universidade Federal do Ceará, Fortaleza, CE.

Triana, S. V. (2012) Capitalismo gore y necropolítica en México contemporáneo. Relaciones Internacionales. Madrid, n. 19, 83-102. Recuperado de: http://www.relacionesinternacionales.info/ojs/article/view/331.html

Valois, L. C. (2017). O direito penal da guerra às drogas ( $2^{\mathrm{a}}$ ed.). Belo Horizonte, MG: D'plácido. 